\title{
Novel compounds in the treatment of lung cancer: current and developing therapeutic agents
}

This article was published in the following Dove Press journal:

Journal of Experimental Pharmacology

16 March 201I

Number of times this article has been viewed

\author{
Rudi Bao \\ Pokman Chan \\ Oncology, Curis Inc, Lexington, \\ MA, USA
}

\begin{abstract}
Lung cancer is the leading cause of cancer-related death in the United States. Though incremental advances have been made in the treatment of this devastating disease during the past decade, new therapies are urgently needed. Traditional cytotoxic agents have been combined with other modalities with improved survival for early-stage patients. Newer cytotoxic agents targeting the same or different mechanisms have been developed at different stages. Optimization of various chemotherapy regimens in different settings is one of the aims of current clinical trials. Some predictive biomarkers (eg, excision repair cross-complementing 1, ERCC1) and histotypes (eg, adenocarcinoma) are found to be associated with resistance/response to some cytotoxic drugs. Another notable advance is the addition of targeted therapy to lung cancer treatment. Targeted agents such as erlotinib and bevacizumab have demonstrated clinical benefits and gained Food and Drug Administration approval for lung cancer. More agents targeting various signaling pathways critical to lung cancer are at different stages of development. Along with the effort of new targeted drug discovery, biomarkers such as epidermal growth factor receptor and anaplastic lymphoma kinase mutations have proven useful for patient selection, and more predictive biomarkers have been actively evaluated in non-small cell lung cancer. The paradigm of lung cancer treatment has shifted towards biomarker-based personalized medicine.
\end{abstract}

Keywords: lung cancer, therapy, cytotoxic agents, targeted agents

\section{Introduction}

Lung cancer is the leading cause of cancer death in the United States, accounting for roughly one-third of all cancer deaths. It has been estimated that in 2010, there were 222,520 new cases and 157,300 deaths from lung cancer.

Lung cancer is not a single disease with a single type of treatment, but rather a group of diseases that need distinct management. Lung cancer is divided into two major categories, non-small cell lung cancer (NSCLC) and small cell lung cancer (SCLC). NSCLC is the most common type of lung cancer, making up nearly $85 \%$ of all cases. It is further divided into three subcategories: squamous cell carcinoma, adenocarcinoma, and large cell carcinoma. Small cell lung cancer makes up the rest. This type of lung cancer is more aggressive and almost always caused by smoking. ${ }^{2}$

The complexity of lung cancer makes its treatment difficult. In the past four decades since President Richard Nixon officially declared "War on Cancer", many cancers have seen their 5-year survival rates increase as a direct result of improvements in screening, diagnosis, and treatment. However, the 5-year survival rate for lung cancer has only modestly increased from $10 \%$ to $15 \% .{ }^{1}$ Much of that advance is due to better surgery and an improved ability to deliver local therapy. Some of this progress is 
due to adjuvant and neoadjuvant therapy for resectable lung cancer and, finally, some is attributable to combined-modality therapy for locally advanced disease. Until very recently, advances in therapy for metastatic disease have contributed little to the overall outcome for this disease.

The development of new classic cytotoxic agents remains an important area of clinical research in lung cancer. Optimization of chemotherapy regimens in different settings (for example, adjuvant, neoadjuvant, and maintenance) is one of the aims of current clinical trials. In addition, genetic biomarkers and histology have been actively explored to select chemotherapy for certain patient populations in order to improve efficacy and/or reduce toxicity.

Another notable advance in lung cancer is the addition of targeted drugs as a result of deeper understanding of lung cancer biology. In addition, molecular biomarkers are increasingly used to tailor treatment, and these are among the new advances that show promise in prolonging progressionfree and overall survival even among those with advanced lung cancer.

\section{Current and developing therapeutic agents for NSCLC Cytotoxic agents}

NSCLC is only moderately sensitive to chemotherapy, with single-agent response rates in the range of $15 \%$ to $30 \%$. Most studies have shown that two agents are better than one. Three agents used in combination do not provide much additional benefit but do cause a number of additional side effects. ${ }^{3}$ Therefore, chemotherapy regimens usually include two drugs, a platinum drug with either an older (etoposide) or newer (taxanes, gemcitabine, pemetrexed or vinorelbine) chemotherapeutic drug. Approximately $80 \%$ of all patients with lung cancer are considered for chemotherapy at some point during the course of their illness. ${ }^{3}$

\section{Platinum compounds}

Cisplatin has been the cornerstone of most combination regimens in advanced NSCLC. Carboplatin is another US Food and Drug Administration (FDA) approved platinum drug which causes less gastrointestinal toxicity, nephrotoxicity, and neurotoxicity but more thrombocytopenia than cisplatin. ${ }^{4}$ American Society of Clinical Oncology guidelines recommend that first-line treatment for NSCLC should include a platinum combination. ${ }^{4}$ In younger patients, with a good performance status or in the adjuvant setting, cisplatin is preferred, but in older patients or those with significant morbidities, carboplatin may be substituted.
Although platinum-based chemotherapy is currently the standard of care in NSCLC, data suggest that certain individual tumors may have inherent resistance to platinum compounds. Platinum disrupts the double-stranded DNA mainly through the formation of intrastrand adducts. Nucleotide excision repair (NER) is the primary DNA repair mechanism that removes platinum-DNA adducts from genomic DNA. Excision repair cross-complementing 1 (ERCC1) is a critical gene on the NER pathway. ${ }^{5}$ Recent studies have found that tumors with high levels of the ERCC1 protein are less likely to respond to platinum compounds. ${ }^{6}$ Holm et al recently reported that ERCC1 expression, as evaluated by immunohistochemistry, was associated with worse outcomes in inoperable NSCLC, particularly in men. ${ }^{7}$ In other studies where ERCC1 mRNA expression has been measured and correlated with the outcome, results have been conflicting. ${ }^{8,9}$ Therefore, prospective clinical studies, use of scientifically validated biomarker assays, and well-annotated clinical data will help to further define ERCC1's role in patient selection for platinum chemotherapy in NSCLC.

Development of new generation platinum compounds with improved efficacy and tolerability continues but has met challenges. The most advanced compounds, satraplatin (JM-216), and picoplatin failed to prolong overall survival in late-stage clinical trials of solid cancer. ${ }^{10}$

\section{Tubulin inhibitors}

Taxanes (paclitaxel and docetaxel) are microtubule stabilizing agents, and have become an integral part of several commonly used chemotherapy regimens in NSCLC. Taxanes inhibit the growth of lung cancer cell lines, exhibit synergistic interaction with other chemotherapy agents, and enhance the efficacy of radiation in vitro. ${ }^{11}$ When used at low doses, they have important antiangiogenic properties. ${ }^{12}$ Several Phase II and III clinical trials have established the efficacy of the taxanes, as single agents and when used in combination with a platinum compound, in the treatment of advanced NSCLC. ${ }^{13-15}$ The use of a taxane in combination with a platinum compound has become an acceptable standard for patients with advanced or metastatic NSCLC. In addition to its efficacy in the first-line therapy of NSCLC, docetaxel is also the FDA-approved second-line agent for recurrent or relapsed NSCLC in the US. Several ongoing trials are comparing the efficacy of combining molecularly targeted agents with taxane-based regimens for the treatment of advanced NSCLC (eg, Clinicaltrials.gov identifier: NCT00976677, NCT00661193). 
Recently, new formulations of taxane such as albuminbound paclitaxel (ABI-007) and paclitaxel poliglumex have been tested in late-stage clinical trials and yielded improved toxicity profiles. ${ }^{16-19}$ Many other novel tubulin inhibitors are at earlier stages of development and appear promising as single agents and in combination regimens. Patupilone (EPO906), ixabepilone (BMS-247550), and KOS-862 (epothilone D) are a class of epothilones that bind to the same site as taxanes, yet are structurally distinct. These epothilone agents have shown activity as second-line therapy even in docetaxel-refractory NSCLC. ${ }^{20-23}$ ABT751 is an agent targeting the colchicine site of tubulin. It has demonstrated activity in taxane-refractory NSCLC patients. ${ }^{24}$ Safer and more effective tubulin inhibitors could replace paclitaxel and docetaxel as standard treatments in NSCLC in the future.

\section{Gemcitabine}

Gemcitabine, a pyrimidine nucleoside antimetabolite agent, is approved by the FDA in combination with cisplatin for the first-line treatment of patients (for whom surgery is not possible) with locally advanced (stage IIIA or stage IIIB) or metastatic (stage IV) NSCLC.

As with ERCC1 for platinum compounds, increased expression of ribonucleotide reductase subunit 1 (RRM1) may serve as a predictor for decreased response to gemcitabine. The $R R M 1$ gene encodes the regulatory subunit of ribonucleotide reductase which converts ribonucleotide 5 -diphosphate to deoxyribonucleotide $5^{\prime}$-diphosphate, which is essential for DNA synthesis. Gemcitabine, an analog of deoxycytidine ( $\left(2^{\prime}, 2^{\prime}\right.$-difluorodeoxycytidine), interferes with the function of ribonucleotide reductase and reduces the pool of deoxyribonucleotide diphosphate available for DNA synthesis. Overexpression of ribonucleotide reductase abrogates gemcitabine depletion of deoxyribonucleotide diphosphate, leading to efficient DNA synthesis and repair. ${ }^{25}$ In a prospective Phase II study of patients with locally advanced NSCLC, increased RRM1 expression was associated with lower response rate following treatment with cisplatin and gemcitabine. ${ }^{26}$ Other retrospective studies also demonstrated poor survival in advanced NSCLC patients with high RRM1 expression. ${ }^{27-29}$ Trials to select chemotherapy based on RRM1 levels in advanced NSCLC are ongoing (Clinicaltrials.gov identifier: NCT00705549, NCT00499109).

\section{Pemetrexed}

Pemetrexed is approved by the FDA as a first-line treatment, in combination with cisplatin, against locally advanced and metastatic NSCLC in patients with non-squamous histology. A Phase III study showed benefits of maintenance use of pemetrexed in this histotype. ${ }^{30}$

Until recently, NSCLC histology was considered to have no influence on responsiveness to chemotherapy. A Phase III trial comparing first-line cisplatin-pemetrexed to cisplatingemcitabine in stage IIIB/IV NSCLC showed statistically similar efficacy. However, in subset analysis, patients with non squamous histology had a statistically better median survival with the cisplatin-pemetrexed combination: for adenocarcinoma (12.6 vs 10.9 months) and in large cell histology (10.4 vs 6.7 months). In contrast, patients with squamous cell histology did better with the cisplatingemcitabine combination (10.8 vs 9.4 months). ${ }^{31}$ As a result, cisplatin-pemetrexed is now the preferred combination for adenocarcinoma of lung cancer.

\section{Other cytotoxic agents}

Etoposide (VP-16) has been approved by the FDA to treat SCLC. It has also been useful for NSCLC in combination with other chemotherapy drugs such as cisplatin or carboplatin. It inhibits the enzyme topoisomerase II, which unwinds DNA, and by doing so causes DNA strands to break.

Vinorelbine is an antimitotic chemotherapy drug that is given as a treatment for some types of cancer, including NSCLC.

Currently, chemotherapy alone has a limited role in curative therapy for NSCLC. For stage IIA, IIB, and IIIA NSCLC, adjuvant or neoadjuvant use of chemotherapy together with surgery have shown a survival benefit. For locally advanced NSCLC, chemotherapy may be considered as part of multimodality therapy. For stage IIIB and IV NSCLC, chemotherapy is used alone as palliative treatment.

Second-line chemotherapy can be used in selected patients with good responses to first-line chemotherapy, good performance status, and a long disease-free period between initial chemotherapy and relapse. Docetaxel and pemetrexed have been approved by FDA in this clinical setting, but other drugs (eg, gemcitabine, vinorelbine), if not used in the first-line regimen, may result in similar clinical benefit. ${ }^{4}$

The concept of maintenance therapy has been introduced in recent years for NSCLC treatment. Multiple clinical trials have been conducted with maintenance therapy following four to six cycles of first-line chemotherapy. These trials have shown improvement in progression-free survival or even overall survival using agents (pemetrexed, docetaxel, and erlotinib) approved as second-line therapy. ${ }^{32,33}$ 


\section{Targeted agents}

With the increased understanding of molecular abnormalities in lung cancer, recent research efforts have focused heavily on identifying molecular targets and using this knowledge to develop molecular-targeted therapies. An important advancement in lung cancer treatment has been the development of such targeted therapies. Targeted treatments attack cancer in more specific ways, usually by interrupting the signaling pathways critical to cancer cell proliferation and survival.

\section{Targeting epidermal growth factor receptor}

Dysregulation of epidermal growth factor receptor (EGFR) is one common abnormality in NSCLC. Stimulation of the EGFR pathway leads to a series of intracellular events culminating in increased mitotic and growth potential, increased ability to metastasize, and increased angiogenesis in the cancer. Cancers with EGFR overexpression have been shown to be associated with increased resistance to therapy, increased metastatic potential, and poorer prognosis. ${ }^{34}$

Gefitinibis the first EGFR tyrosine kinase inhibitor (TKI) entering clinical trials for NSCLC. It binds reversibly to the adenosine triphosphate (ATP) binding site of the EGF receptor, blocking signal transduction to downstream molecules. ${ }^{34}$

In two large Phase II trials, IDEAL1 and IDEAL2 (Iressa Dose Evaluation in Advanced Lung Cancer), single-agent gefitinib achieved objective tumor responses of $18.4 \%$ and $11.8 \%$, and disease control rates (complete and partial responses plus stable disease) of $54.4 \%$ and $42.2 \%$, respectively, in recurrent advanced NSCLC. ${ }^{35}$ Based on these promising results, gefitinib was granted accelerated FDA approval as a third-line therapy in May 2003. ${ }^{36}$ However, results from a subsequent large Phase III randomized clinical trial (Iressa Survival Evaluation in Lung Cancer, ISEL) showed that gefitinib did not provide a survival benefit over placebo for the majority of participants. ${ }^{37}$ As a result, in June 2005, the FDA limited the use of gefitinib to those patients who were benefiting from treatment, and for use in clinical trials.

In August 2009, the results of a Phase III trial called IPASS (Iressa Pan Asia Study) comparing gefitinib with carboplatin-paclitaxel in the first-line setting in Asian patients who had adenocarcinoma and who had never smoked or who were former light smokers (none in the prior 15 years), were reported. ${ }^{38}$ Gefitinib demonstrated better progressionfree survival compared with the combination chemotherapy of carboplatin and paclitaxel. Patients receiving gefitinib had a higher response rate ( $43 \%$ vs $32 \%$ ), with similar median survival (18.6 vs 17.3 months). Patients who were positive for the EGFR gene mutation ( $\mathrm{n}=261)$ experienced significantly longer progression-free survival when enrolled in the gefitinib group compared with those who received carboplatinpaclitaxel. Conversely, patients who were negative for the mutation $(n=176)$ had significantly longer progression-free survival in the carboplatin-paclitaxel group. This marked the first time a single targeted therapy has shown significantly longer progression-free survival over chemotherapy. Currently, gefitinib remains an approved treatment in Europe and in 36 other countries for NSCLC whose tumors have tested positive for the EGFR mutation.

Erlotinib is another EGFR inhibitor with a similar mechanism of action to gefitinib. ${ }^{39} \mathrm{In}$ a randomized, placebocontrolled, double-blind trial (BR.21; N = 731) to determine whether erlotinib prolongs survival in NSCLC after failure of first-line or second-line chemotherapy, erlotinib demonstrated improved response rates ( $8 \%$ vs $<1 \%$ ), and overall survival (6.7 vs 4.6 months) compared with the placebo group. ${ }^{40}$ This led to the FDA approval of erlotinib in the second-line setting in 2004.

The efficacy and safety of erlotinib as maintenance treatment of NSCLC were later demonstrated in a randomized, double-blind, placebo-controlled trial called SATURN (Sequential Tarceva in Unresectable NSCLC) conducted in 26 countries, in 889 patients with locally advanced or metastatic NSCLC whose disease did not progress during first-line platinum-based chemotherapy ${ }^{41}$ Patients were randomized 1:1 to receive erlotinib $150 \mathrm{mg}$ or placebo orally once daily until disease progression or unacceptable toxicity. The primary objective of the study was to determine if the administration of erlotinib after standard platinum-based chemotherapy in the treatment of NSCLC resulted in improved progression-free survival when compared with placebo, in all patients or in patients with EGFR immunohistochemistrypositive tumors. The results show that compared with placebo, erlotinib maintenance therapy significantly improves progression-free survival (12.3 vs 11.1 weeks) and overall survival (12.0 vs 11.0 months) in patients with advanced NSCLC. Based on the SATURN results, the FDA in 2010 expanded erlotinib's approval to maintenance use for locally advanced or metastatic NSCLC that has not progressed after four cycles of platinum-based first-line chemotherapy.

Erlotinib is currently being tested in a wide variety of clinical trials for NSCLC, including as a first-line treatment; early stage treatment; in combination with chemotherapies; and after surgical removal of lung cancer.

The finding that the EGFR activating mutation is closely associated with sensitivity to EGFR tyrosine kinase inhibitors 
revolutionized the care of patients with lung cancer. Earlier studies with either erlotinib orgefitinib showed better response rates and survival with females, individuals of Asian descent, and nonsmokers, particularly those with adenocarcinoma histology, and among them, especially those with bronchioalveolar cancer. ${ }^{36,41}$ Research subsequently showed that $E G F R$ activating mutations (mainly exon 19 deletions or L858R mutation) confer tumor sensitivity to EGFR tyrosine kinase inhibitors and these mutations are more frequent in the subpopulations of NSCLC patients mentioned above. ${ }^{42,43}$ These mutations occur in $10 \%$ of lung adenocarcinoma specimens in the United States and in 30\% in Asian samples. Since these observations were first made, it has become clear that the best predictor of a meaningful clinical response to EGFR TKI is the presence of EGFR activating mutations in the tumor, so that, pretreatment testing for EGFR mutation via direct sequencing or mutation-specific detection, is now endorsed by many leading institutions. It has become common practice that NSCLC patients positive for EGFR activating mutations are treated with EGFR TKI as frontline therapy, which is supported by multiple Phase II and III clinical trials of both erlotinib and gefitinib including the IPASS trial as described above. ${ }^{35,44-46}$

Neratinib (HKI-272) is one of the second generationEGFR/HER2 tyrosine kinase inhibitors with a quinazoline core structure that can irreversibly bind to the ATP pocket of EGFR kinase. It was designed, potentially, to overcome secondary resistance to erlotinib or gefitinib. The secondary EGFR kinase mutation T790M accounts for roughly $50 \%$ of cases of acquired resistance. Laboratory studies have indicated that HKI-272 can inhibit the growth of lung cancer cells bearing EGFR T790M mutation, suggesting a potential benefit for patients with this mechanism of acquired resistance to erlotinib. ${ }^{47}$ However, the clinical efficacy of these irreversible inhibitors has been limited by toxicities, such as diarrhea and rash, associated with wild-type EGFR inhibition. ${ }^{48}$ Interestingly, WZ4002, an early development compound with a pyrimidine core structure, can strongly inhibit T790M EGFR without affecting wild-type EGFR in cultured cells, in contrast to the quinazoline-based inhibitors. ${ }^{49}$ Its clinical utility has yet to be confirmed.

Another strategy to overcome EGFR T790M mutation is to target heat shock protein 90 (HSP90), a molecular chaperone for many oncoproteins critical to cancer. ${ }^{50}$ It has been demonstrated that HSP90 inhibitors can downregulate multiple oncoproteins including mutated EGFR in lung cancer cell lines bearing an T790M mutation, and prolong the survival of mice carrying orthotopic lung tumors established from EGFR T790M-mutant cell lines. ${ }^{50,51}$ Currently, a few HSP90 inhibitors are being evaluated broadly in clinical trials. These agents include the natural product 17-AAG (17-allylamino-17-demethoxygeldanamycin) and its derivative IPI-504, and the small-molecule inhibitor Debio-0932 (formerly CUDC-305). ${ }^{51-53}$ By overcoming gatekeeper residue mutations, such a strategy, if successful, may be of value for the treatment of a broad range of mutant receptordriven cancers.

Among the means of acquired resistance to EGFR inhibitors, the T790M mutation mechanism only accounts for $50 \%$ of all cases. Another mechanism is the activation of alternative receptor tyrosine kinase pathways (eg, MET, IGFR, PDGFR), thereby bypassing EGFR signaling. ${ }^{54}$ Such compensatory mechanisms also often play an important role in primary resistance to EGFR TKI, which after all occurs in most NSCLC cases. One strategy to overcome primary and/or secondary resistance is the use of multitargeted agents that can interrupt multiple signaling nodes/pathways simultaneously. CUDC-101, a small-molecule inhibitor of the histone deacetylase, EGFR and HER2, is designed to overcome EGFR TKI resistance by blocking key regulators of several compensatory signaling pathways, in addition to its direct targets, EGFR/HER2 signaling pathways. ${ }^{54,55}$ Currently, the compound is being tested in Phase IB clinical trials for solid tumors including NSCLC (Clinicaltrials.gov identifier: NCT01171924).

Besides EGFR TKI, monoclonal antibody against EGFR extracellular domain is another approach to targeting EGFR pathway. Cetuximab, a chimeric human-murine monoclonal antibody against EGFR, has been approved to treat colorectal and some head and neck cancers. Data released in June 2008 show survival advantages in NSCLC patients in the first-line setting. ${ }^{56}$ In this study of 1125 patients with advanced NSCLC expressing EGFR by immunohistochemistry (First-Line Treatment for Patients with Epidermal growth factor inhibitor EGFR-EXpressing Advanced NSCLC, FLEX), those given the combination treatment (cisplatin-vinorelbine plus cetuximab) lived an average of 11.3 months vs 10.1 months for those who received only chemotherapy (cisplatin-vinorelbine). Further studies on molecular markers to predict response are ongoing, and will be required to determine optimal strategies for the use of these agents in a manner that generates more meaningful clinical benefits. It has recently been shown that colon cancer patients who have a mutation of $K R A S$, do not derive a benefit from cetuximab treatment. This finding has changed the practice of cetuximab use in colon cancer. ${ }^{57}$ However, it does not 
seem that the same applies to NSCLC yet. ${ }^{58}$ Rather, further studies are needed to delineate which biomarkers have values in making treatment decision for NSCLC.

Synergy between cetuximab and radiation therapy has been observed in head and neck cancer. ${ }^{59}$ This combination is currently being investigated in NSCLC and may or may not confirm synergy in this indication.

\section{Targeting angiogenesis}

Angiogenesis is the process by which new blood vessels grow from pre-existing vessels. This critical step enables tumor expansion, local invasion, and dissemination. ${ }^{60}$ As a result, targeting angiogenesis has become an attractive approach in cancer treatment. An extensive array of antiangiogenic compounds is currently in preclinical development, with many now entering the clinic and/or achieving FDA approval. Presently, the monoclonal antibody bevacizumab is an approved treatment for NSCLC. The kinase inhibitors vandetanib, sunitinib, and sorafenib are currently in latestage clinical trials.

Bevacizumab was approved in October 2006 for use with chemotherapy (carboplatin and paclitaxel) in patients with NSCLC that is not surgically removable and is locally advanced, recurrent, or metastatic. Bevacizumab, however, is not appropriate for use in patients with squamous cell carcinoma.

A Phase III ECOG (Eastern Cooperative Oncology Group) study in 878 patients with recurrent or advanced NSCLC has shown that addition of bevacizumab to standard first-line carboplatin-paclitaxel resulted in significant prolongation of survival. ${ }^{61}$ The median overall survival was improved (12.3 vs 10.3 months), as was the response rate (35\% vs $15 \%$ ) compared with chemotherapy alone. Despite increased hemorrhagic complications and treatment-related deaths, bevacizumab has now been approved for use in this setting in combination with chemotherapy.

Bevacizumab in combination with cisplatin-gemcitabine has also been studied in a Phase III trial (Avastin in Lung, AVAiL) as first-line therapy for non-squamous NSCLC, and yielded modest improvement in progression-free survival (6.7 vs 6.1 months), but not overall survival. ${ }^{62}$

Numerous studies have focused on identifying subpopulations that may benefit from the addition of bevacizumab to chemotherapy. As in other cancer indications, hypertension is emerging as a predictor of clinical benefit from bevacizumab in NSCLC (ECOG 4599). ${ }^{63}$

Sunitinib is a small-molecule inhibitor of VEGF receptor (VEGFR) 1, VEGFR-2, fetal liver tyrosine kinase receptor 3
(FLT3), stem cell factor receptor (KIT), and platelet-derived growth factor receptor-alpha/beta (PDGFR $\alpha / \beta) .{ }^{64}$ This compound has been approved to treat metastatic renal cell carcinoma (RCC). A Phase II study of sunitinib in refractory NSCLC demonstrated single-agent activity in previously treated patients with recurrent and advanced NSCLC, with a level of activity similar to currently approved agents. ${ }^{65}$ However, clinical trials with sunitinib have raised concerns over its toxicity. ${ }^{66}$ Furthermore, a trial of sunitinib in combination with erlotinib vs erlotinib alone (SUN1087) demonstrated a statistically significant improvement in progression-free but not in overall survival, in patients with previously treated advanced NSCLC. ${ }^{67}$ Nonetheless, sunitinib as maintenance therapy in previously treated advanced NSCLC is being investigated (Clinicaltrials.gov identifier:NCT00693992).

Sorafenib is another small-molecule inhibitor of the multiple kinases involved in angiogenesis and is currently marketed worldwide for the treatment of hepatocellular carcinoma, and advanced RCC. ${ }^{68}$ Unfortunately, in a Phase III trial named NExUS (NSCLC research Experience Utilizing Sorafenib) evaluating sorafenib vs placebo in combination with two chemotherapeutic agents, gemcitabine and cisplatin, in patients with advanced NSCLC, sorafenib did not meet the primary endpoint of improving overall survival in the first-line setting, though a positive secondary endpoint of progression-free survival was observed. ${ }^{69}$ Currently, sorafenib is being evaluated in a variety of treatment settings for patients with NSCLC, including a Phase III monotherapy study in the third- and fourth-line setting and Phase II studies in combination with other therapies as second-line treatment. $^{70}$

Vandetanib is a small-molecule inhibitor of the VEGFR, EGFR, and rearranged during transfection (RET) tyrosine kinases. ${ }^{71}$ It has been tested as second-line treatment combined with docetaxel in a Phase III trial (ZODIAC), ${ }^{72}$ as second-line treatment combined with pemetrexed in a Phase II randomized trial (ZEAL), ${ }^{73}$ as second- or thirdline treatment compared with erlotinib in a Phase III trial (ZEST), ${ }^{74}$ and second-line treatment compared with placebo in previously treated patients in a Phase III trial (ZEPHYR). ${ }^{75}$ The results indicate that vandetanib has some activity, but lacks overall survival improvement. It was initially submitted to FDA in June 2009 for approval in combination with chemotherapy in patients with advanced NSCLC. However, the application was withdrawn in October of the same year for lack of benefit when administered along with chemotherapy. 


\section{Targeting EML4-ALK}

The EML4-ALK mutation, a fusion of the anaplastic lymphoma kinase (ALK) with echinoderm microtubule-associated protein-like 4 (EML4), has been identified in roughly $6 \%$ of NSCLC cases. ${ }^{76,77}$ Several clinical features, including no or light history of smoking, male gender, younger age (median age approximately 50), lack of EGFR or KRAS mutation and an adenocarcinoma history, are associated with the EML4$A L K$ mutation. ${ }^{78-80}$ Therefore, a trial can be enriched for a patient population with EML4-ALK mutation by these clinical features. ${ }^{78} \mathrm{PF}-02341066$ (crizotinib), a small-molecule inhibitor of c-MET and ALK, is the most advanced ALK inhibitor in development. ${ }^{81-83}$ In a Phase I/II trial, impressive results have been reported in patients with underlying EML4-ALK mutation. EML4-ALK fusion was found in 19 out of 141 patients. Among them, 10/19 (53\%) demonstrated drug response and disease stabilization at 8 weeks, lasting up to 40 weeks. The side effects associated with PF-02341066 treatment seemed tolerable. ${ }^{83}$ The trial strongly suggests the importance of incorporating prospective molecular enrichment strategies for patient selection which may be generally useful in future clinical trials for targeted therapies. ${ }^{84}$ Based on this promising observation, several other clinical studies including Phase III trials on patients restricted to those with EML4-ALK fusion mutation, have been initiated (Clinicaltrials.gov identifier: NCT00932893). Results from these trials are awaited.

\section{Targeting IGF-I and IGF-IR}

The insulin-like growth factor 1 (IGF-1) receptor (IGF-1R) is anovel target for cancer therapy since high level expression of IGF-1R occurs in up to $70 \%$ of NSCLC patients. ${ }^{85,86}$ IGF-1R signaling involves the activation of intracellular pathways including the RAS/RAF/MAP kinase and the PI3K (phosphatidylinositol-3-kinase) pathways, all of which are critical to cancer proliferation and survival. ${ }^{87}$

CP-751,871 (figitumumab), a monoclonal antibody against IGF-1R, has been assessed in a randomized Phase II study in patients with advanced NSCLC without prior treatment. ${ }^{88}$ In this study, 156 patients were enrolled to receive carboplatin and paclitaxel with or without two doses of CP-751,871 (10 mg/kg or $20 \mathrm{mg} / \mathrm{kg}$ ). Objective response was observed in $54 \%$ of patients treated with a combination of antibody and chemotherapy, versus $42 \%$ of patients treated with chemotherapy alone. In addition, the response rate was highest (78\%) in patients with a squamous histology in the high dose CP-751,871 arm, suggesting dysregulation of IGF-1R pathway may be common in this histotype ${ }^{89}$ Additionally, there was a trend towards improved progression-free survival in the high dose group ${ }^{88} \mathrm{~A}$ randomized, open-label, Phase III trial assessing IGF-1R antibody and chemotherapy in combination was planned but withdrawn prior to enrollment (Clinicaltrials. gov identifier: NCT00907504).

Besides monoclonal antibodies, several small-molecule inhibitors of the IGF-1R tyrosine kinase are also tested at various development stages in solid tumors including NSCLC (AEW541, OSI-906, BMS-536924, etc). ${ }^{90}$

\section{Targeting c-MET}

$M E T$ is a proto-oncogene encoding a heterodimeric transmembrane receptor. The MET kinase receptor and its ligand are responsible for key intracellular signaling cascades associated with cell growth, proliferation, invasion, and angiogenesis. ${ }^{91}$ Overexpression of c-MET is found in $60 \%$ to $80 \%$ of NSCLC patients, and $20 \%$ of them carry c-MET mutations..$^{92}$ Amplification of c-MET also occurs in acquired EGFR TKI-resistant NSCLC patients without EGFR mutations (eg, T790M), suggesting that c-MET may be a relevant target for some NSCLC patients with resistance to gefitinib or erlotinib. ${ }^{93}$ Simultaneous targeting of c-MET and EGFR may serve as a treatment strategy for NSCLC since coactivation of both receptor pathways is frequently observed. ${ }^{94}$ Several c-MET antagonists are currently under clinical investigation. The most advanced is PF-02341066, a multi-kinase inhibitor that has demonstrated an overall response rate of $53 \%$ and disease control of $79 \%$, at 8 weeks in NSCLC. ${ }^{95}$ At present, this compound is in Phase II/III clinical development in NSCLC patients at a dose of $250 \mathrm{mg}$ twice daily either in monotherapy or in combination with EGFR inhibitors (Clinicaltrials.gov identifier: NCT00932893, NCT00932451, NCT00965731).

Other small-molecule multi-kinase inhibitors, such as XL-184, ARQ197, and MK-2461 have also entered clinical trials in NSCLC. ${ }^{92}$

Finally, SCH-900105 (AV-229), a humanized monoclonal antibody, and AMG102, a fully human monoclonal antibody against free HGF (hepatocyte growth factor, the ligand for c-MET), are being tested in Phase I and II clinical trials in lung cancer in combination with EGFR TKI (Clinicaltrials. gov identifier: NCT01039948, NCT01233687). ${ }^{92}$

\section{Targeting the PI3K/AKT/mTOR pathway}

The PI3K signaling pathway is crucial in cell proliferation, survival, metabolism, and apoptosis inhibition. ${ }^{96}$ Abnormalities in PI3K/AKT/mTOR pathway are implicated in many cancers, including NSCLC.${ }^{97}$ This pathway is typically activated at an early stage in the development of 
lung cancer, suggesting that it may be a relevant target for NSCLC therapy. ${ }^{98}$

Intriguingly, a number of signaling nodes of the PI3K pathway can be targeted individually for cancer therapy. Inhibitors of these molecular targets have shown activity in NSCLC cell lines in vitro and in vivo, and some compounds have entered early clinical trials. ${ }^{99}$

The serine-threonine kinase mTOR downstream of PI3KAKT plays a critical role in signaling caused by activation of upstream receptor tyrosine kinases. ${ }^{99}$ Rapamycin derivatives of the mTOR complex 1 (mTOR1) inhibitors, temsirolimus (CCI-779) and everolimus (RAD001), have been approved for the treatment of metastatic RCC and are currently being evaluated in NSCLC. Antitumor activity has been observed with several of these inhibitors in Phase I/II studies in NSCLC. ${ }^{100-105}$ Of note, a Phase I study with everolimus has shown inhibition of the proangiogenic growth factors in response to radiation-induced stress. ${ }^{100}$ However, a subsequent Phase II study with everolimus therapy alone has been disappointing. ${ }^{101}$ Everolimus is also being evaluated in NSCLC in combination with erlotinib or gefitinib, and docetaxel in relapsed NSCLC. ${ }^{103,104}$

Another mTOR inhibitor, temsirolimus, has been assessed in SCLC as maintenance therapy, but also concluded with disappointing results. ${ }^{102}$ Two Phase II studies of temsirolimus as monotherapy or in combination with pemetrexed, are being conducted in advanced or refractory NSCLC (Clinicaltrials.gov identifier: NCT00079235, NCT00921310). A novel mTOR inhibitor, ridaforolimus, formerly known as AP23573 and MK-8669, is currently being investigated in a Phase II study in NSCLC patients with KRAS mutations (Clinicaltrials.gov identifier: NCT00818675) after partial response was observed in a Phase I trial in NSCLC. ${ }^{105}$

Kinase inhibitors that target both mTOR complex 1 and 2 (mTORC2) are believed to be more effective than the current rapamycin analogs. OSI-027 and AZD8055, two ATP-competitive inhibitors of the mTORC1 and mTORC2, are currently in early clinical trials for solid tumors and lymphoma (Clinicaltrials.gov identifier: NCT00698243, NCT00731263).

Numerous compounds targeting PI3K have been introduced into clinical trials. BEZ235, animidazoquinoline derivative and dual PI3K/mTOR inhibitor, was the first to enter the clinic in 2006. Dual PI3K/mTOR inhibitors XL765, GDC-0941, BGT226, and single PI3K inhibitors BKM120, XL147, GSK1059615, are also under clinical development. ${ }^{99}$ Simultaneous inhibition of both PI3K and mTOR might potentially increase inhibition of signaling throughout the pathway's cascade of signaling events.

\section{Targeting KRAS}

$E G F R$ and KRAS are the two most commonly mutated oncogenes in lung cancer. $K R A S$ links $E G F R$ signaling to intracellular molecules involved in cell proliferation and survival. Mutations in KRAS are found in approximately $15 \%$ of advanced NSCLC patients. Activating mutations in $K R A S$ can bypass EGFR signaling and mediate the resistance to EGFR inhibitors. ${ }^{106-108}$

There are no approved KRAS inhibitors on the market today for the treatment of lung carcinomas. However, the development of therapeutic agents targeting KRAS inhibition continues. MT477, a novel quinoline with both in vivo and in vitro inhibition activities against cell lines with mutated KRAS, might have potential for future development as an agent targeting KRAS mutant tumors. ${ }^{109}$ Clinical trials of a farnesyl transferase inhibitor which alters RAS membrane localization have not demonstrated efficacy in $K R A S$ mutant tumors. ${ }^{110}$ Molecular targets downstream of KRAS, such as MEK and RAF, have also been actively evaluated, so far with little promise. ${ }^{11,112}$

\section{Targeting polo-like kinases}

Polo-like kinases (PLKs) are highly conserved serine/ threonine kinases which control cell division. PLK mRNA is highly expressed in most cancers, but not in surrounding healthy noncancer cell types, making it an attractive target in cancer treatment. ${ }^{113,114}$ Several PLK inhibitors have been tested in clinical trials for treatment of cancer. Among them, BI2536 and BI6727 are the most advanced. ${ }^{115}$ In a Phase II study in NSCLC patients, BI2536 was delivered on day 1 $(200 \mathrm{mg})$ or on days $1-3\left(3 \times 50 \mathrm{mg} /{ }^{3} \times 60 \mathrm{mg}\right)$ on a 21 -day treatment program. Clinical benefit was observed in $54 \%$ of patients. Adverse events, including nausea and fatigue, were mild. ${ }^{116}$ BI6727, a follow-up compound with improved pharmacological profiles over BI2536, is being tested in combination with pemetrexed in advanced NSCLC (Clinicaltrials.gov identifier: NCT00824408). ${ }^{117}$ Several other PLK inhibitors, including HMN-214, ON019190.Na, and GSK461364 have also entered clinical trials for lung cancer. ${ }^{114,118,119}$

\section{Proteasome inhibitors}

Proteasome inhibitors have effective antitumor activity in cell culture, where they induce apoptosis by disrupting the regulated degradation of pro-growth cell cycle proteins. ${ }^{120}$ Bortezomib is a dipeptidyl boronic acid that serves as a spe- 
cific and selective reversible inhibitor of the $26 \mathrm{~S}$ proteosome and has been approved for the treatment of multiple myeloma. ${ }^{120}$ A Phase II study of 114 NSCLC patients treated with bortezomib plus gemcitabine/carboplatin showed 1-year and 3-year survival rates of $47 \%$ and $19 \%$, respectively. ${ }^{121}$ A subsequent Phase II trial with monotherapy of bortezomib in chemotherapy-naïve patients with advanced stage NSCLC has seen modest results, suggesting that bortezomib is most likely to gain clinical value in combination with other therapeutic agents. ${ }^{122}$ Clinical trials testing bortezomib in combination with cytotoxic or targeted agents in NSCLC are ongoing.

\section{Alternative approaches}

Several types of vaccines for boosting the body's immune response against lung cancer cells are being tested in clinical trials. These vaccines are designed to help treat, not prevent, lung cancer, in contrast to traditional vaccines such as those used to prevent infections like measles or mumps. Due to limited side-effects, these types of treatments may be useful in people who cannot tolerate other treatments. Vaccines can be made from lung cancer cells or cell components, such as parts of proteins commonly found in cancer cells. For example, L-BLP25 is a vaccine made up of Mucin 1 protein commonly expressed in NSCLC. A small study in 171 patients with advanced NSCLC suggested that it may improve survival time. ${ }^{123}$ Three larger Phase III trials are being conducted worldwide to confirm this possibility. Other vaccines such as those directed against N-glycolyl-GM3 ganglioside, Toll-like receptor-9, EGFR, granulocyte macrophage colony stimulating factor, and melanoma-associated antigen (MAGE)-A3 are also being evaluated in clinical trials in NSCLC. ${ }^{124}$

Gene therapy has become an attractive approach following the discovery of gene dysregulation in lung cancer. The gene therapy approach is still not validated and only limited clinical activity has been observed in clinical trials. Gene targeting strategies include introducing suicide genes, replacing defective tumor-suppressor genes, or inactivating oncogenes. The most extensively tested gene therapy is the replacement of the p53 gene which is mutated in $40 \%$ to $70 \%$ of NSCLC samples and which is associated with resistance to chemotherapy and radiotherapy. ${ }^{125}$ Phase I studies of p53 replacement with various viral vectors injected directly or delivered by bronchoalveolar lavage have suggested clinical response with evidence of targeted gene expression in lung tumor lesions. ${ }^{126,127}$ However, a large Phase II study indicated that recombinant adenovirus p53 (Ad. P53) provides little benefit over chemotherapy. ${ }^{128}$ Until more efficient vectors are developed, the potential for gene therapy in NSCLC is very limited.

Photodynamic therapy is currently in clinical trials for patients with limited SCLC whose cancer is causing an endobronchial obstruction. ${ }^{129,130}$ The photosensitizing agent, typically comprising a porphyrin, a naturally occurring substance in the body, is first injected into the patient a few hours before surgery. The agent then selectively accumulates in rapidly growing cells such as cancer cells. During surgery, a certain wavelength of light which activates the photosensitizing agent is applied causing the production of a toxin that accumulates in the cancer cells and ultimately destroys them.

\section{Current and developing therapeutic agents for SCLC}

Chemotherapy is the cornerstone for SCLC treatment. In limited stage disease, chemotherapy and radiotherapy are often used together. Extensive stage disease is treated primarily with combination chemotherapy. ${ }^{131}$

\section{Cytotoxic agents}

Many chemotherapy agents are active against SCLC. Combination chemotherapy of two to three agents has been proven to be more effective in SCLC than single drug therapy. Reported response rates range from $80 \%$ to $100 \%$ for limited disease and $60 \%$ to $89 \%$ for extensive disease. ${ }^{131}$ The most commonly used two-drug combination is a platinum compound plus etoposide, whereby four to six cycles of treatment are typically administered. ${ }^{131}$ Ongoing clinical trials focus on examining the effectiveness of different chemotherapy combinations using established and newer chemotherapy agents. High doses of chemotherapy followed by a bone marrow transplant have also been explored. ${ }^{132}$ Two studies have indicated that high-dose chemotherapy plus autologous stem cell transplant improve progressionfree survival and overall survival in patients with limited SCLC. ${ }^{133,134}$ Listed below are a few newer cytotoxic agents that have been added to the arsenal of treatment choices in recent years.

Topotecan is a semisynthetic derivative of camptothecin and is an antitumor drug with topoisomerase I-inhibitory activity. ${ }^{135}$ The pill form of topotecan was approved in October 2007, for the treatment of relapsed SCLC patients with a prior complete or partial response who are at least 45 days from the end of first-line chemotherapy. Injectable topotecan has been an approved treatment for SCLC since 1998. 
Amrubicin (SM-5887) is the hydrochloride salt of a third-generation synthetic 9-amino-anthracycline with antineoplastic activity. Amrubicin intercalates into DNA and inhibits the activity of topoisomerase II, resulting in the inhibition of DNA replication, and RNA and protein synthesis, followed by cell growth inhibition and cell death. This agent has demonstrated a higher level of antitumor activity than conventional anthracycline drugs without exhibiting any indication of the cumulative cardiac toxicity common to this class of compounds. ${ }^{136}$ Amrubicin was granted fast-track designation by FDA in September 2008 for SCLC treatment after first-line chemotherapy.

\section{Targeted agents}

Targeted drugs have been explored in combination with chemotherapy, but have yielded inconclusive results. Currently, a few randomized clinical trials are ongoing to further assess targeted agents in SCLC. To date, it is generally accepted that the administration of targeted agents as induction treatment of SCLC does not improve the outcomes reached with chemotherapy alone. Targeted agents tested in this setting include the KIT inhibitor STI-571, the Bcl-2 antisense agent G3139, and the antiangiogenesis antibody bevacizumab. ${ }^{137-139}$ Targeted agents have also been tested as maintenance/ consolidation therapy, for instance, the matrix metalloproteinase inhibitors BB2516 (marimastat) and BAY 12-9566 (tanomastat), the immune stimulator BEC2 (mitumomab), the VEGFR/EGFR/HER2 tyrosine kinase inhibitor ZD6474 (vandetanib), immunomodulatory and the antiangiogenic compound thalidomide. However, no positive result has been reported in this setting. ${ }^{140-145}$

\section{Conclusion}

Over the past few years, advances have been made in the treatment of lung cancer mainly due to the addition of targeted agents and the use of multimodality therapies. In addition, predictive biomarkers such as EGFR and $A L K$ mutations help greatly to tailor targeted agents to the appropriate patient population. Even for traditional chemotherapeutic agents, biomarkers such as ERCC1 can help in patient selection in order to reduce toxicity and improve efficacy. Many clinical trials are ongoing to define the roles of targeted therapies along with relevant biomarkers, and to optimize regimens of multimodality therapies in different settings in lung cancer. It will be exciting to see the results from these trials during the next few years and whether truly significant improvements of overall and progression-free survival can be achieved.

\section{Acknowledgment}

We would like to thank Dr Carmen Pepicelli for helpful discussion of the content.

\section{Disclosure}

Authors are employees of Curis, Inc.

\section{References}

1. American Cancer Society: Cancer Facts and Figures 2010. Atlanta, GA: American Cancer Society, 2010.

2. Herbst RS, Heymach JV, Lippman SM. Molecular origins of cancer: lung cancer. $N$ Engl J Med. 2008;359:1367-1380.

3. National Comprehensive Cancer Network. National Comprehensive Cancer Network Guidelines V. 2009. www.ncen.org/professionals/ physician_gls/PDF/nscl.pdf.

4. Azzoli CG, Baker S, Temin S, et al. American Society of Clinical Oncology clinical practice guideline update on chemotherapy for stage IV non-small-cell lung cancer. J Clin Oncol. 2009;27:6251-6266.

5. Gossage L, Madhusudan S. Current status of excision repair cross complementing-group 1 (ERCC1) in cancer. Cancer Treat Rev. 2007; 33:565-577.

6. Ryu JS, Hong YC, Han HS, et al. Association between polymorphisms of ERCC1 and XPD and survival in non-small-cell lung cancer patients treated with cisplatin combination chemotherapy. Lung Cancer. 2004; 44:311-316.

7. Holm B, Mellemgaard A, Skov T, Skov BG. Different impact of excision repair cross-complementation group 1 on survival in male and female patients with inoperable non-small-cell lung cancer treated with carboplatin and gemcitabine. J Clin Oncol. 2009;27:4254-4259.

8. Lord RV, Brabender J, Gandara D, et al. Low ERCC1 expression correlates with prolonged survival after cisplatin plus gemcitabine chemotherapy in non-small-cell lung cancer. Clin Cancer Res. 2002;8: 2286-2291.

9. Booton R, Ward T, Ashcroft L, et al. ERCC1 mRNA expression is not associated with response and survival after platinum-based chemotherapy regimens in advanced non-small-cell lung cancer. J Thorac Oncol. 2007;2:902-906.

10. Edelman, Martin J. MD. Novel cytotoxic agents for non-small cell lung cancer. J Thorac Oncol. 2006;1:752-755.

11. Francis PA, Kris MG, Rigas JR, Grant SC, Miller VA. Paclitaxel (Taxol) and docetaxel (Taxotere): Active chemotherapeutic agents in lung cancer. Lung Cancer. 1995;12(Suppl 1):S163-S172.

12. Grant DS, Williams TL, Zahaczewsky M, Dicker AP. Comparison of antiangiogenic activities using paclitaxel (taxol) and docetaxel (taxotere). Int J Cancer. 2003;104:121-129.

13. Ranson M, Davidson N, Nicolson M, et al. Randomized trials of paclitaxel plus supportive care versus supportive care for patients with advanced non-small cell lung cancer. J Natl Cancer Inst. 2000;92: 1074-1080.

14. Cerny T, Kaplan S, Pavlidis N, et al. Docetaxel (Taxotere) is active in non-small cell lung cancer: a phase II trial of the EORTC Early Clinical Trials Group (ECTG). Br J Cancer. 1994;70:384-387.

15. Bono IP, Kim K, Fairclough D, et al. Comparison of survival and quality of life in advanced non-small cell lung cancer patients treated with two dose levels of paclitaxel combined with cispaltin versus etoposide with cisplatin: results of the Eastern Cooperative Oncology Group trial. J Clin Oncol. 2000;18:623-631.

16. Singer JW, Baker B, De Vries P, et al. Poly-(L)-glutamic acid-paclitaxel (CT-2103)[XYOTAX], a biodegradable polymeric drug conjugate: characterization, preclinical pharmacology, and preliminary clinical data. Adv Exp Med Biol. 2003;519:81-99.

17. Bonomi P, Paz-Ares L, Langer C, et al. XYOTAX TM vs. docetaxel for the second-line treatment of non-small cell lung cancer: the STELLAR 2 phase III study. Lung Cancer. 2005;49:S35. 
18. Langer CJ, Socinski MA, O’Byrne KJ. Paclitaxel poliglumex (PPX)/ carboplatin vs. paclitaxel/carboplatin for the treatment of PS2 patients with chemotherapy-naive advanced non-small cell lung cancer: a phase III study. Proc Am Soc Clin Oncol. 2006;23:623s.

19. Desai N, Trieu V, Yao Z, et al. Increased antitumor activity, intratumor paclitaxel concentrations, and endothelial cell transport of cremophorfree, albumin-bound paclitaxel, ABI-007, compared with cremophorbased paclitaxel. Clin Cancer Res. 2006;12:1317-1324.

20. Rubin EH, Rothermel J, Tesfaye F, et al. Dose-finding study of weekly single-agent patupilone in patients with advanced solid tumors. J Clin Oncol. 2006;23:9120-9129.

21. Mani S, McDaid H, Hamilton A, et al. Phase I clinical and pharmacokinetic study of BMS-247550, a novel derivative of epothilone B, in solid tumors. Clin Cancer Res.2004;10:1289-1298.

22. Yee L, Lynch T, Villalona-Calero M, et al. A phase II study of KOS-862 (epothilone D) as second line therapy in non-small cell lung cancer. Abstract]. Proc Am Soc Clin Oncol. 2006;23:652s.

23. Edelman MJ, Breton JL, Sandler A, et al. Randomized phase II study of epothilone analog BMS-247550 in patients with non-small cell lung cancer who have failed first line platinum based chemotherapy. Lung Cancer. 2003;41:S5.

24. Yee KW, Hagey A, Verstovsek S, et al. Phase 1 study of ABT-751, a novel microtubule inhibitor, in patients with refractory hematologic malignancies. Clin Cancer Res. 2006;11:6615-6624.

25. Elledge SJ, Zhou Z, Allen JB. Ribonucleotide reductase: regulation, regulation, regulation. Trends Biochem Sci. 1992;17:119-123.

26. Bepler G, Kusmartseva I, Sharma S, et al. RRM1 modulated in vitro and in vivo efficacy of gemcitabine and platinum in non-small-cell lung cancer. J Clin Oncol. 2006;24:4731-4737.

27. Davidson JD, Ma L, Flagella M, et al. An increase in the expression of ribonucleotide reductase large subunit 1 is associated with gemcitabine resistance in non-small cell lung cancer cell lines. Cancer Res. 2004;64: 3761-3766.

28. Rosell R, Danenberg K, Alberola V, et al. Ribonucleotide reductase mRNA expression and survival in gemcitabine/cisplatin-treated advanced non-small-cell lung cancer patients. Clin Cancer Res. 2004; 10:1318-1325

29. Reynolds C, Obasaju C, Michael J. Randomized phase III trial of gemcitabine-based chemotherapy with in situ RRM1 and ERCC1 protein levels for response prediction in non-small-cell lung cancer. J Clin Oncol. 2009;27:5808-5815.

30. Ciuleanu TE, Brodowicz T, Belani CP, et al. Maintenance pemetrexed plus best supportive care (BSC) versus placebo plus BSC: a phase III study. J Clin Oncol. 2008;26(Suppl 15):S426.

31. Scagliotti GV, Parikh P, von Pawel J, et al. Phase III study comparing cisplatin plus gemcitabine with cisplatin plus pemetrexed in chemotherapy-naive patients with advanced-stage non-small-cell lung cancer. J Clin Oncol. 2008;26:3543-3551.

32. Fidias PM, Dakhil SR, Lyss AP, et al. Phase III study of immediate compared with delayed docetaxel after front-line therapy with gemcitabine plus carboplatin in advanced non-small-cell lung cancer. J Clin Oncol. 2009;27:591-598.

33. Ciuleanu T, Brodowicz T, Zielinski C, et al. Maintenance pemetrexed plus best supportive care versus placebo plus best supportive care for non-small-cell lung cancer: a randomised, double-blind, phase 3 study. Lancet. 2009;374:1432-1440.

34. Mendelsohn J, Baselga J. Status of epidermal growth factor receptor antagonists in the biology and treatment of cancer. J Clin Oncol. 2003;21:2787-2799

35. Lynch TJ, Bell D, Haber D, et al. Correlation of molecular markers including mutations with clinical outcomes in advanced non small cell lung cancer (NSCLC) patients (pts) treated with gefitinib, chemotherapy or chemotherapy and gefitinib in IDEAL and INTACT clinical trials. Proc Am Soc J Clin Oncol. 2005;23(Suppl 16):S622 (abstract 7006).

36. Cohen MH, Williams GA, Sridhara R, et al. United States Food and Drug Administration Drug Approval summary: Gefitinib (ZD1839; Iressa) tablets. Clin Cancer Res. 2004;10:1212-1218.
37. Thatcher N, Chang A, Parikh P, et al. Gefitinib plus best supportive care in previously treated patients with refractory advanced non-small-cell lung cancer: results from a randomised, placebo-controlled, multicentre study (Iressa Survival Evaluation in Lung Cancer). Lancet. 2005;366: 1527-1537.

38. Yang CH, Fukuoka, Mok TS, et al. Final overall survival (OS) results from a phase 3, randomized, open-label, first-line study of gefitinib $(\mathrm{G}) \mathrm{V}$ carboplatin/paclitaxel $(\mathrm{C} / \mathrm{P})$ in clinically selected patients with advanced nonsmall cell lung cancer (NSLC) in Asia (IPASS). Program and abstracts of the 35 th European Society of Medical Oncologists (ESMO) Congress; 2010 October 8-12; Milan, Italy. Abstract LBA212.

39. Tsao MS, Sakurada A, Cutz JC, et al. Erlotinib in lung cancer molecular and clinical predictors of outcome. NEngl JMed. 2005;353: 133-144.

40. Shepherd FA, Pereira JR, Ciuleanu T, et al. Erlotinibin previously treated non-small-cell lung cancer. $N$ Engl J Med. 2005;353:123-132.

41. Cappuzzo F, Ciuleanu T, Stelmakh L, et al. SATURN: Erlotinib as maintenance treatment in advanced non-small cell lung cancer: a multicenter, randomized placebo-controlled phase 3 study. Lancet Oncol. 2010;11:521-529.

42. Pao W, Miller V, Zakowski M, et al. EGF receptor gene mutations are common in lung cancers from "never smokers" and are associated with sensitivity of tumors to gefitinib and erlotinib. Proc Natl Acad Sci US A. 2004;101:13306-13311.

43. Rosell R, Moran T, Queralt C, et al. Screening for epidermal growth factor receptor mutations in lung cancer. $N$ Engl J Med. 2009;361:958-967.

44. Mitsudomi T, Morita S, Yatabe Y, et al. Gefitinib versus cisplatin plus docetaxel in patients with non-small-cell lung cancer harbouring mutations of the epidermal growth factor receptor (WJTOG3405): an open label, randomized phase 3 trial. Lancet Oncol. 2010;11:121-128.

45. Zhou C, Wu YL, Chen G, et al. Efficacy results from the randomized phase III OPTIMAL (CTONG 0802) study comparing first-line erlotinib versus carboplatin (CBDCA) plus gemcitabine (GEM), in Chinese advanced non-small-cell lung cancer (NSCLC) patients (PTS) with EGFR activating mutations. Program and abstracts of the 35 th European Society of Medical Oncologists (ESMO) Congress; 2010 October 8-12; Milan, Italy. Abstract LBA13.

46. Jänne PA, Wang XF, Socinskiet MA, et al. Randomized phase II trial of erlotinib (E) alone or in combination with carboplatin/paclitaxel (CP) in never or light former smokers with advanced lung adenocarcinoma: CALGB 30406. J Clin Oncol. 2010;28(Suppl 15):abstract 7503.

47. Kwak EL, Sordella R, Bell DW, et al. Irreversible inhibitors of the EGF receptor may circumvent acquired resistance to gefitinib. Proc Natl Acad Sci U S A. 2005;102:7665-7670.

48. Sequist LV, Besse B, Lynch TJ, et al. Neratinib, an irreversible pan-ErbB receptor tyrosine kinase inhibitor: results of a phase II trial in patients with advanced non-small-cell lung cancer. 2010;28:3076-3083.

49. Zhou W, Ercan D, Chen L, et al. Novel mutant-selective EGFR kinase inhibitors against EGFR T790M. Nature. 2009;462:1070-1074.

50. Bao R, Lai C, Qu H, et al. CUDC-305, a novel synthetic HSP90 inhibitor with unique pharmacological properties for cancer therapy. Clin Cancer Res. 2009;15:4046-4057.

51. Bao R, Lai C, W D, et al. Targeting heat shock protein 90 with CUDC305 overcomes erlotinib resistance in non-small-cell lung cancer. $\mathrm{Mol}$ Cancer Ther. 2009;8:3296-3306.

52. Shimamura T, Lowell AM, Engelman JA, Shapiro GI. Epidermal growth factor receptors harboring kinase domain mutations associate with the heat shock protein 90 chaperone and are destabilized following exposure to geldanamycins. Cancer Res. 2005;64:6401-6408.

53. Ge J, Normant E, Porter JP, et al. Design, synthesis, and biological evaluation of hydroquinone derivatives of 17-amino-17-demethoxygel danamycin as potent, water-soluble inhibitors of Hsp90. J Med Chem. 2006;49:4606-4615

54. Lai C, Bao R, Tao X, et al. CUDC-101, a multitargeted inhibitor of histone deacetylase, epidermal growth factor receptor, and human epidermal growth factor receptor 2, exerts potent anticancer activity. Cancer Res. 2010;70:3647-3656. 
55. Cai X, Zhai HX, Wang J, et al. Discovery of (7-(4-(3-Ethynylphenylamino)-7methoxyquinazolin-6-yloxy)-N-hydroxyheptanamide)(CUDC-101) as a potent multi-acting HDAC, EGFR and HER2 inhibitor for the treatment of cancer. J Med Chem. 2010;53:2000-2009.

56. Pirker R, Pereira JR, Szczesna A, et al. Cetuximab plus chemotherapy in patients with advanced NSCLC (FLEX): an open-label randomised phase III trial. Lancet. 2009;373:1525-1531.

57. Cutsem EV, Kohne C-H, Hitre E, et al. Cetuximab and chemotherapy as initial treatment for metastatic colorectal cancer. $N$ Engl J Med. 2009;360:1408-1417.

58. Khambata-Ford S, Harbison CT, Hart LL, et al. Analysis of potential predictive markers of cetuximab benefit in BMS099, a phase III study of cetuximab and first-line taxane/carboplatin in advanced non-smallcell lung cancer. J Clin Oncol. 2010;28:918-927.

59. Bonner J, Harari P, Giralt J, et al. Radiotherapy plus cetuximab for squamous-cell carcinoma of the head and neck. NEngl J Med. 2006;354: 567-578.

60. Folkman J. Endothelial cells and angiogenic growth factors in cancer growth and metastasis. Introduction. Cancer Metastasis Rev. 1990;9: 171-174.

61. Sandler A, Gray R, Perry MC, et al. Paclitaxel-carboplatin alone or with bevacizumab for non-small-cell lung cancer. $N$ Engl J Med. 2006;355: 2542-2550.

62. Martin R, Joachim VP, Petr Z, et al. BO17704: a phase III study of first-line cisplatin and gemcitabine with bevacizumab or placebo in patients with advanced or recurrent non-squamous non-small cell lung cancer (NSCLC): C1-06. J Thorac Oncol. 2007;2:S360-S361.

63. Dahlberg SE, Sandler AB, Brahmer JR. Clinical course of advanced non-small-cell lung cancer patients experiencing hypertension during treatment with bevacizumab in combination with carboplatin and paclitaxel on ECOG 4599. J Clin Oncol. 2010;28:949-954.

64. Mendel DB, Laird AD, Xin X, et al. In vivo antitumor activity of SU11248, a novel tyrosine kinase inhibitor targeting vascular endothelial growth factor and platelet-derived growth factor receptors: determination of a pharmacokinetic/pharmacodynamic relationship. Clin Cancer Res. 2003;9:327-337.

65. Novello S, Seagliotti GV, Rosell R, et al. Phase II study of continuous daily sunitinib dosing in patients with previously treated advanced non-small cell lung cancer. Br J Cancer. 2009;101:1543-1548.

66. Chu TF, Rupnick MA, Kerkela R, et al. Cardiotoxicity associated with tyrosine kinase inhibitor sunitinib. Lancet. 2007;370:2011-2019.

67. Govindan R, Krazakowski M, Szczesna A, et al. Sunitinib in combination with erlotinib for the treatment of advanced/metastatic non-small cell lung cancer (NSCLC): a phase III study CTS 2010. Chicago Multidisciplinary Symposium in Thoracic Oncology; 2010 December 9-11; Chicago. Abstract LBPL2.

68. Wilhelm SM, Adnane L, Newell P, Villanueva A, Llovet JM, Lynch M. Preclinical overview of sorafenib, a multikinase inhibitor that targets both Raf and VEGF and PDGF receptor tyrosine kinase signaling. Mol Cancer Ther. 2008;7:3129-3140.

69. Scagliotti G, von Pawel J, Reck M. Sorafenib plus carboplatin/paclitaxel in chemonaive patients with stage IIIB-IV non-small cell lung cancer (NSCLC): interim analysis (IA) results from the phase III, randomized, double-blind, placebo-controlled, ESCAPE (Evaluation of Sorafenib, Carboplatin, and Paclitaxel Efficacy in NSCLC) Trial. 1st European Lung Cancer Conference. April 24-26, 2008. Geneva, Switzerland: Abstract 6.

70. Blumenschein G Jr. Sorafenib in lung cancer: clinical developments and future directions. J Thorac Oncol. 2008;3(6 Suppl 2): S124-S127.

71. Morabito A, Piccirillo MC, Costanzo R, et al. Vandetanib: an overview of its clinical development in NSCLC and other tumors. Drugs Today (Barc). 2010;46:683-698.

72. Herbst RS, Sun Y, Eberhardt WE, et al. Vandetanib plus docetaxel versus docetaxel as second-line treatment for patients with advanced non-small-cell lung cancer (ZODIAC): a double-blind, randomised, phase 3 trial. Lancet Oncol. 2010;11:619-626.
73. De Boer R, Vansteenkiste J, Humblet Y, et al. Vandetanib with pemetrexed in patients with previously treated non-small cell lung cancer (NSCLC): an open-label, multicenter phase I study. J Clin Oncol. 2007;25(Suppl 18):abstract 7654.

74. Natale RB, Thongprasert S, Greco FA, et al. Vandetanib versus erlotinib in patients with advanced non-small cell lung cancer (NSCLC) after failure of at least one prior cytotoxic chemotherapy: a randomized, double-blind phase III trial (ZEST). J Clin Oncol.2009;27(Suppl 15): abstract 8009 .

75. Lee J, Hirsh V, Park K, et al. Vandetanib versus placebo in patients with advanced non-small cell lung cancer (NSCLC) after prior therapy with an EGFR tyrosine kinase inhibitor (TKI): a randomized, double-blind phase III trial (ZEPHYR). J Clin Oncol. 2010;28(Suppl 15):abstract 7525 .

76. Soda M, Choi YL, Enomoto M, et al. Identification of the transforming EML4-ALK fusion gene in non-small-cell lung cancer. Nature. 2007;448:561-566.

77. Martelli MP, Sozzi G, Hernandez L, et al. EML4-ALK rearrangement in non-small-cell lung tissues. Am J Pathol. 2009;174:661-670.

78. Shaw AT, Yeap BY, Mino-Kenudson M, et al. Clinical features and outcome of patients with non-small-cell lung cancer who harbor EML4ALK. J Clin Oncol. 2009;27:4247-4253.

79. Choi YL, Takeuchi K, Soda M, et al. Identification of novel isoforms of the EML4-ALK transforming gene in non-small-cell lung cancer. Cancer Res. 2008;68:4971-4976.

80. Wong DW, Leung EL, So KK, et al. The EML4-ALK fusion gene is involved in various histologic types of lung cancers from non-smokers with wild-type EGFR and KRAS. Cancer Res. 2008;115:1723-1733.

81. Zhou HY, Li Q, Lee JH, et al. An orally available small-molecule inhibitor of c-met, PF-02341066, exhibits cytoreductive antitumor efficacy through antiproliferative and antiangiogenic mechanisms. Cancer Res. 2007;67:4408-4417.

82. Christensen JG, Zou HY, Arango ME, et al. Cytoreductive antitumor activity of PF-02341066, a novel inhibitor of anaplastic lymphoma kinase and c-Met, in experimental models of anaplastic large-cell lymphoma. Mol Cancer Ther. 2007;6:3314-3322.

83. Kwak EL, Camidge DR, Clark J, et al. Clinical activity observed in phase I dose escalation trial of an oral c-met and ALK inhibitor, PF-02341066. J Clin Oncol. 2009;27(Suppl 15):abstract 3509.

84. LiY, Ye X, Liu J, Zha J, Pei L. Evaluation of EML4-ALK fusion proteins in non-small-cell lung cancer using small molecule inhibitors. Neoplasia. 2011;13:1-11

85. Batus M, Fidler MJ, Basu S, et al. Frequency of insulin-like growth factor 1 (IGFR-1) expression and correlation with clinical and selected molecular parameters in advanced non-small-cell lung cancer (NSCLC) patients. J Clin Oncol. 2008;26:22080.

86. Ouban A, Muraca P, Yeatman T, Coppola D. Expression and distribution of insulin-like growth factor-1 receptor in human carcinomas. Hum Pathol. 2003;34:803-808

87. Werner H, Le Roith D. New concepts in regulation and function of the insulin-like growth factors: implications for understanding normal growth and neoplasia. Cell Mol Life Sci. 2000;57:932-942.

88. Karp DD, Paz-Ares LG, Novello S, et al. Phase II study of the antiinsulin-like growth factor type I receptor antibody CP-751,871 in combination with paclitaxel and carboplatin in previously treated, locally advanced or metastatic non-small-cell lung cancer. J Clin Oncol. 2009;27:2516-2522.

89. Han JY, Choi BG, Choi JY, Lee SY, Ju SY. The prognostic significance of pretreatment plasma levels of insulin-like growth factor (IGF)-1, IGF-2, and IGF binding protein-3 in patients with advanced non-small cell lung cancer. Lung Cancer. 2006;54:227-234.

90. Hewish M, Chau I, Cunningham D. Insulin-like growth factor 1 receptor targeted therapeutics: novel compounds and novel treatment strategies for cancer medicine. Recent Pat Anticancer Drug Discov. 2009:4:54-72.

91. Cipriani NA, Abidoye OO, Vokes E, Salgia R. MET as a target for treatment of chest tumors. Lung Cancer. 2009;63:169-179. 
92. Eder JP, Woude FV, Boerner SC, Boerner SA, LoRusso PM. Novel therapeutic inhibitors of the c-Met signaling pathway in cancer. Clin Cancer Res. 2009;15:2207-2214.

93. Bean J, Brennan C, Shih JY, et al. MET amplification occurs with or without T790M mutations in EGFR mutant lung tumors with acquired resistance to gefitinib or erlotinib. Proc Natl Acad Sci USA. 20076;104:20932-20937.

94. Puri N, Salgia R. Syngergism of EGFR and c-Met pathways, cross-talk and inhibition, in non-small cell lung cancer. J Carcinog. 2008;7:1-8.

95. Kwak EL, Camidge DR, Clark J, et al. Clinical activity observed in a phase I dose-escalation trial of an oral MET and ALK inhibitor, PF-02341066. J Clin Oncol. 2009;27(Suppl 15):abstract 2509.

96. Shaw RI, Cartley LC. Ras, PI(3)K and mTOR signaling controls tumour growth. Nature. 2006;441:424-430.

97. Yamamoto H, Shigematsu H, Nomura M, et al. PIK3CA mutations and copy number gains in human lung cancers. Cancer Res. 2008;68:6913-3921.

98. West KA, Linnoila IR, Belinsky SA, Harris CC, Dennis PA. Tobacco carcinogen-induced cellular transformation increases activation of the phosphatidylinositol 3'-kinase/Akt pathway in vitro and in vivo. Cancer Res. 2004;64:446-451.

99. Liu P, Cheng H, Roberts TM, Zhao JJ. Targeting the phosphoinositide 3kinase pathway in cancer. Nat Rev Drug Discov. 2009;8:627-644.

100. O'Donnel A, Faivre S, Burris HA, et al. Phase I pharmacokinetic and pharmacodynamic study of the oral mammalian target of rapamycin inhibitor everolimus in patients with advanced solid tumors. $J$ Clin Oncol. 2008;26:1588-1595.

101. Papadimitraikopoulou V, Soria JC, Douillard JY, et al. A phase II study of RAD001 (R) (everolimus) monotherapy in patients (pts) with advanced non-small cell lung cancer (NSCLC) failing prior platinumbased chemotherapy (C) or prior C and EGFR inhibitors (EGFR-1). J Clin Oncol. 2007;25(Suppl 18):abstract 7589.

102. Pandya KJ, Levy DE, Hidalgo M, et al. A randomized, phase II ECOG trial of two dose levels of temsirolimus (CCI-779) in patients with extensive stage small cell lung cancer in remission after induction chemotherapy: a preliminary report. J Clin Oncol. 2005;23(Suppl 16):abstract 7005.

103. Milton DT, Riely GJ, Azzoli CG, et al. Phase 1 trial of everolimus and gefitinib in patients with advanced non-small cell lung cancer. Cancer. 2007;110:599-605.

104. Khuri FR, Harvey D, Saba NF, et al. Everolimus, an mTOR inhibitor, in combination with docetaxel for recurrent/refractory NSCLC: a phase I study. J Clin Oncol. 2009;27(Suppl 15):S421.

105. Mita MM, Mita AC, Chu QS, et al. Phase I trial of the novel mammalian target of rapamycin inhibitor deforolimus (AP23573; MK-8669) administered intravenously daily for 5 days every 2 weeks to patients with advanced malignancies. J Clin Oncol. 2008;26:361-367.

106. Pao W, Wang TY, Riely GJ, et al. KRAS mutations and primary resistance of lung adenocarcinomas to gefitinib or erlotinib. PLoS Med. 2005;2:e17.

107. Marks JL, Broderick S, Zhou Q, et al. Prognostic and therapeutic implications of EGFR and KRAS mutations in resected lung adenocarcinoma. J Thorac Oncol. 2008;3:111-116.

108. Riely GJ, Kris MG, Rosenbaum D, et al. Frequency and distinctive spectrum of KRAS mutations in never smokers with lung adenocarcinoma. Clin Cancer Res. 2008;14:5731-5734.

109. Jasinski P, Zwolak P, Terai K, Dudek A. Novel Ras pathway inhibition induces apoptosis and growth inhibition of k-ras-mutated cancer cells in vitro and in vivo. Transl Res. 2008;152:203-212.

110. Appels NM, Beijnen JH, Schellens JH. Development of farnesyl transferase inhibitors: a review. Oncologist. 2005;10:565-578.

111. Balko JM, Jones BR, Coakley VL, Black EP. Combined MEK and EGFR inhibition demonstrates synergistic activity in EGFR-dependent NSCLC. Cancer Biol Ther. 2009;8:522-530.

112. Mahoney CL, Choudhury B, Davies H, et al. LKB1/KRAS mutant lung cancers constitute a genetic subset of NSCLC with increased sensitivity to MAPK and mTOR signaling inhibition. Br J Cancer. 2009; 100:370-375.
113. Jackson JR, Patrick DR, Dar MM, Huang PS. Targeted anti-mitotic therapies: can we improve on tubulin agents? Nat Rev Cancer. 2007;7: 107-117.

114. Schöffski P. Polo-like kinase (PLK) inhibitors in preclinical and early clinical development in oncology. Oncologist. 2009;14:559-570.

115. Steegmaier M, Hoffmann M, Baum A, et al. BI 2536, a potent and selective inhibitor of polo-like kinase 1, inhibits tumor growth in vivo. Curr Biol. 2007; 17:316-322.

116. Von Pawel, Reck M, Digel W, et al. Randomized phase II trial of two dosing schedules of BI 2536, a novel Plk-1 inhibitor, in patients with relapsed advanced or metastatic non-small cell lung cancer (NSCLC). J Clin Oncol. 2008;26(Suppl):abstract 8030.

117. Rudolph D, Steegmaier M, Hoffmann M, et al. BI 6727, a polo-like kinase inhibitor with improved pharmacokinetic profile and broad antitumor activity. Clin Cancer Res. 2009;15:3094-3102.

118. Garland LL, Taylor C, Pilkington DL, Cohen JL, Von Hoff DD. A phase I pharmacokinetic study of HMN-214, a novel oral stilbene derivative with polo-like kinase- 1 interacting properties, in patients with advanced solid tumors. Clin Cancer Res. 2006;12:5182-5189.

119. Olmos D, Allred A, Sharma R, et al. Phase I first-in-human study of the polo-like kinase-1 selective inhibitor, GSK461364, in patients with advanced solid tumors. J Clin Oncol. 2009;27(Suppl 15):abstract 3536.

120. Adams J, Palombella VJ, Sauville EA, et al. Proteasome inhibitors: a novel class of potent and effective antitumor agents. Cancer Res. 1999;59:2615-2622.

121. Davies AM, Chansky K, Lara PN, et al. Southwest Oncology Group. Bortezomib plus gemcitabine/carboplatin as first-line treatment of advanced non-small-cell lung cancer: a phase II Southwest Oncology Group Study (S0339). J Thorac Oncol. 2009;41:87-92.

122. Li T, Ho L, Piperdi B, et al. Phase II study of the proteasome inhibitor bortezomib (PS-341, Velcade) in chemotherapy-naïve patients with advanced stage non-small cell lung cancer (NSCLC). Lung Cancer. 2010;68:89-93.

123. Butts C, Murray N, Maksymiuk A, et al. Randomized phase IIB trial of BLP25 liposome vaccine in stage IIIB and IV non-small-cell lung cancer. J Clin Oncol. 2005;23:6674-6681.

124. Gridelli C, Rossi A, Maione P, et al. Vaccines for the treatment of non-small cell lung cancer: a renewed anticancer strategy. Oncologist. 2009;40:909-920.

125. Bunz F, Hwang PM, Torrance C, et al. Disruption of p53 in human cancer cells alters the responses to therapeutic agents. J Clin Invest. 1999; 104:263-269

126. Roth JA, Nguyen D, Lawrence DD, et al. Retrovirus-mediated wildtype p53 gene transfer to tumors of patients with lung cancer. Nat Med. 1996;2:985-991.

127. Nemunaitis J, Swisher SG, Timmons T, et al. Adenovirus-mediated p53 gene transfer in sequence with cisplatin to tumors of patients with non- small cell lung cancer. J Clin Oncol. 2000;18:609-622.

128. Schuler M, Herrmann R, Jacques LP, et al. Adenovirus-mediated wild-type p53 gene transfer in patients receiving chemotherapy for advanced non-small-cell lung cancer: results of a multicenter phase II study. J Clin Oncol. 2001;19:1750-1758.

129. Kato H, Harada M, Ichinose S, et al. Photodynamic therapy (PDT) of lung cancer: experience of the Tokyo Medical University. Photodiagnosis Photodyn Ther. 2004;1:49-55.

130. Sutedja TG, Postmus PE. Photodynamic therapy in lung cancer: a review. J Photochem Photobiol B. 1996;36:199-204.

131. Jackman DM, Johnson BE. Small-cell lung cancer. Lancet. 2005;366: 1385-1396.

132. Elias AJ, Ibrahim J, Skarin AT, et al. Dose-intensive therapy for limited-stage small-cell lung cancer: long-term outcome. J Clin Oncol. 1999;17:1175-1184.

133. Fetscher S, Brugger W, Engelhardt R, et al. Standard- and high-dose etoposide, ifosfamide, carboplatin, and epirubicin in 100 patients with small-cell lung cancer: a mature follow-up report. Ann Oncol. 1999;10:561-567. 
134. Kiura K, Ueoka H, Tabata M, et al. Phase II study of high-dose ifosfamide, carboplatin and etoposide with autologous peripheral blood stem cell transplantation for small-cell lung cancer. Proc Am Soc Clin Oncol. 2003;22:632(abstract 2540).

135. Staker BL, Hjerrild K, Feese MD, Behnke CA, Burgin AB, Stewart L. The mechanism of topoisomerase I poisoning by a camptothecin analog. Proc Natl Acad Sci U S A. 2002;99:15387-15392.

136. Ueoka H, Ohnoshi T, Kimura I. New anthracycline analogues in the treatment of lung cancer (in Japanese). Gan To Kagaku Ryoho. 1992; 19:2146-2149.

137. Spigel DR, Hainsworth JD, Simons L, et al. Irinotecan, carboplatin, and imatinib in untreated extensive-stage small-cell lung cancer: a phase II trial of the Minnie Pearl Cancer Research Network. J Thorac Oncol. 2007;2:854-861.

138. Rudin CM, Kozloff M, Hoffman PC, et al. Phase I study of G3139, a bcl-2 antisense oligonucleotide, combined with carboplatin and etoposide in patients with small-cell lung cancer. J Clin Oncol. 2004;22: 1110-1117.

139. Horn L, Dahlberg SE, Sandler AB, et al. Phase II study of cisplatin plus etoposide and bevacizumab for previously untreated, extensivestage small-cell lung cancer: Eastern Cooperative Oncology Group Study E3501. J Clin Oncol. 2009;27:6006-6011.

140. Michael M, Babic B, Khokha R, et al. Expression and prognostic significance of metalloproteinases and their tissue inhibitors in patients with small-cell lung cancer. J Clin Oncol. 1999;17:1802-1808.
141. Shepherd FA, Giaccone G, Seymour L, et al. Prospective, randomized, double-blind, placebo-controlled trial of marimastat after response to first-line chemotherapy in patients with small-cell lung cancer: a trial of the National Cancer Institute of Canada - Clinical Trials Group and the European Organization for Research and Treatment of Cancer. J Clin Oncol. 2002;20:4434-4439.

142. Rigas JR, Denham CA, Rinaldi D, et al. Adjuvant targeted therapy in unresectable lung cancer: the results of two randomized placebocontrolled trials of BAY 12-9566, a matrix metalloproteinase inhibitor (MMPI). Lung Cancer. 2003;41(Suppl 2):S34 (abstract O107).

143. Arnold AM, Seymour L, Smylie M, et al. Phase II Study of vandetanib or placebo in small-cell lung cancer patients after complete or partial response to induction chemotherapy with or without radiation therapy: National Cancer Institute of Canada clinical trials group study BR.20. J Clin Oncol. 2007;25:4278-4284.

144. Giaccone G, Debruyne C, Felip E, et al. Phase III study of adjuvant vaccination with Bec2/bacille Calmette-Guérin in responding patients with limited-disease small-cell lung cancer (European Organisation for Research and Treatment of Cancer 08971-09871B; Silva study). $J$ Clin Oncol. 2005;23:6854-6864.

145. Dowlati A, Subbiah S, Cooney M, et al. Phase II trial of thalidomide asmaintenance therapy for extensive stage small cell lung cancer after response to chemotherapy. Lung Cancer. 2007;56:377-381.
Journal of Experimental Pharmacology

\section{Publish your work in this journal}

The Journal of Experimental Pharmacology is an international, peerreviewed, open access journal publishing original research, reports, reviews and commentaries on all areas of laboratory and experimental pharmacology. The manuscript management system is completely online and includes a very quick and fair peer-review system.

\section{Dovepress}

Visit http://www.dovepress.com/testimonials.php to read real quotes from published authors. 